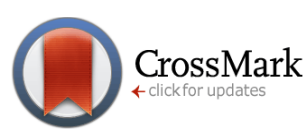

*For correspondence:

pkngoc@hcmus.edu.vn

Competing interests: The authors declare that no competing interests exist.

Received: 29 September 2016 Accepted: 20 November 2016 Published: 02 December 2016

Copyright The Author(s) 2016. This article is published with open access by BioMedPress (BMP).

This article is distributed under the terms of the Creative Commons Attribution License (CC-BY 4.0) which permits any use, distribution, and reproduction in any medium, provided the original author(s) and the source are credited.

\section{Xenotransplantation of human umbilical cord derived stem cells for treatment of type 1 diabetes mellitus in mice}

\author{
Loan Thi-Tung Dang ${ }^{1}$, Anh Nguyen-Tu Bui ${ }^{1}$, \\ Cong Le-Thanh Nguyen ${ }^{1}$, Nhat Chau Truong ${ }^{1}$, Anh Thi-Van Bui ${ }^{1}$, \\ Phuong Thi-Bich Le ${ }^{2}$, Ngoc Kim Phan ${ }^{1, *}$
}

\author{
${ }^{1}$ Laboratory of Stem Cell Research and Application, University of Science, Vietnam \\ National University, Ho Chi Minh city, Viet Nam \\ ${ }^{2}$ Stem Cell Unit, Van Hanh General Hospital, Ho Chi Minh city, Viet Nam
}

\begin{abstract}
Introduction: Type 1 diabetes mellitus disease (T1D) is an autoimmune disease in which pancreatic islets are attacked by the host's immune system. Although this disease can be treated using some of the current methods, resistance to therapy can develop over time after a long usage of the treatments. Therefore, new strategies to treat T1D have been suggested. This study aims to treat T1D using a new approach to target this autoimmune disease; the approach involves the use of mesenchymal stem cells (MSCs) to induce immune modulation. Methods: Umbilical cord derived MSCs (UC-MSCs) were evaluated in this study. The cells were confirmed to be MSCs by surface profile markers and by in vitro differentiation potential into osteoblasts, adipocytes and chondroblasts. The MSCs were evaluated in a Type 1 diabetic mouse model (induced by streptozotocin (STZ)); MSCs were xenografted at a dose of $2.10^{6}$ cells per mouse in $100 \mathrm{uL}$ of saline. T1D mice injected with saline were used as placebo. Mice were monitored for body weight, blood glucose, blood insulin, glucose tolerance test and pancreas histological analysis. Results: Results showed that UC-MSC xenotransplantation could improve diabetes in mice. Mouse body weight significantly increased after 6 weeks of treatment. Blood glucose levels markedly decreased while blood insulin levels strongly increased towards normal range. Recovery of the insulin positive Langerhans cells was confirmed by histological analysis. Conclusion: Overall, our findings suggest that UC-MSC transplantation is a promising therapy for T1D treatment.
\end{abstract}




\section{Keywords}

Immune modulation; Mesenchymal stem cells; Modulatist; Stem cell therapy; Type 1 diabetes mellitus

\section{Introduction}

Diabetes mellitus is the common disease in the world. It was known as an endocrine disorder characterized by inadequate production or use of insulin, resulting in abnormally high blood glucose levels. High levels of blood glucose lead to the formation of reactive advanced glycation end-products that cause multiple complications, including blindness, kidney failure, cardiovascular disease, stroke, neuropathy and vascular dysfunction (Nathan, 1993; Tripathi and Srivastava, 2006). There are two main kinds of diabetes mellitus: diabetes type 1 and type 2. Type 1 diabetes mellitus is regarded as an autoimmune disease in which pancreatic beta cells are destroyed by host immune cells, whereas type 2 diabetes mellitus results from insulin resistance and impaired glucose tolerance (Association, 2006).

Nowadays, although diabetes mellitus type 1 can be treated by supplement of insulin, complications can arise from insulin injection and insulin resistance, which can reduce the benefits of the treatments. To overcome pancreas degeneration associated with diabetes mellitus type 1, there have been several approached aimed at promoting pancreatic regeneration. The first approach is pancreas/islet transplantation (Froud et al., 2005; Shapiro et al., 2000). Islet transplantation therapy is thought to provide good patient outcome. However, few islets are available for transplantation (Rother and Harlan, 2004); pooled islets isolated from two pancreases are typically just enough to treat a single patient.

Recently, stem cell therapies have been investigated for treatment of diabetes. Using hematopoietic stem cell transplantation (HSCT), type 1 diabetes mellitus was shown to be effectively treated (Burt et al., 2002; Voltarelli et al., 2007). HSCT provides a new immune system to replace the impaired one (Burt et al., 2002). Although HSCT has been reported as a promising therapy for T1D, there have been limitations to this method. The main challenges include lack of HSC samples that matching the patient's human leukocyte antigens (HLA) and lack of sources of HSCs (Chhabra and Brayman, 2013).

In this study, we examine a new approach in T1D treatment, based on immune modulation mediated by mesenchymal stem cells (MSCs). Immune modulation refers to the capacity of MSCs to selectively impact (namely suppress) the 
immune system. Immune cells that are the targets of MSC-mediated immune suppression include lymphocytes, dendritic cells; immune cells activated by MSCs include T-regulatory cells (Aggarwal and Pittenger, 2005; Rasmusson, 2006). Since immunomodulation by MSCs was discovered, more than 10 years ago, MSCs have increasingly been studied in the clinic for immune related diseases, especially in graft-versus-host disease (GVHD) (Bartholomew et al., 2002).

Indeed, the first stem cells (Prochymal), based on bone marrow (BM) derived allogeneic MSCs, were approved in 2012 in Canada. Since then, several other countries have begun evaluating Prochymal to manage GVHD (Chen et al., 2014; Kurtzberg et al., 2014). Recently, another form of MSCs was approved in Japan for GVHD (Konishi et al., 2016). The potency of MSCs is related to mechanisms such as contact reaction and mainly production of cytokines, including hepatic growth factor (HGF), transforming growth factor-beta (TGF-b), interleukin (IL)-10, prostaglandin E2 (PGE2), and human leukocyte antigen (HLA)G5. In this study, human umbilical cord tissue derived mesenchymal stem cells (hUC-MSCs) were investigated as treatment for T1D in mice induced by STZ.

\section{Methods}

\section{Cell culture}

Human umbilical cord mesenchymal stem cells (MSCs) were isolated from human umbilical cord tissues according to a protocol from our laboratory (Pham et al., 2016; Van Pham et al., 2016). Briefly, the umbilical cords were collected from the local hospitals with provision of consent forms. They were transferred to the laboratory for isolation of UC-MSCs. The cord tissue was dissected into small fragments with Wharton's jelly. They were then washed twice with PBS and placed into a T-25 flask with $1 \mathrm{~mL}$ of culture medium (MSCCult Medium, Regenmed Lab). The flasks were incubated at $37^{\circ} \mathrm{C}$ for 7 days. After appearance of cells and migration from the fragments, fresh medium was replenished every 3 days until a confluency of $70-80 \%$ was reached. The cell samples were subcultured to the $5^{\text {th }}$ passage prior to use in experiments.

\section{Immunophenotyping by flow cytometry}

Cells were washed twice in PBS containing 1\% bovine serum albumin (SigmaAldrich, St. Louis, MO). Cells were stained with anti-CD14-FITC, anti- CD34FITC, anti- CD44-PE, anti-CD45-FITC, anti- CD73-FITC, anti-CD90- PE, or antiHLA-DR-FITC antibody (all antibodies were purchased from BD Biosciences, San Jose, CA). Stained cells were analyzed by a FACSCalibur flow cytometer (BD Biosciences). Isotype controls were used in all analyses. 


\section{In vitro differentiation}

For differentiation into adipogenic cells, the cells were plated and cultured for 21 days in DMEM/F12 medium containing $0.5 \mathrm{mM} / \mathrm{L}$ 3-isobutyl- 1-methylxanthine, $1 \mathrm{nM}$ dexamethasone, $0.1 \mathrm{mM}$ indomethacin, and 10\% FBS (all purchased from Sigma-Aldrich). Adipogenic differentiation was evaluated by observing, via microscopy, lipid droplets in cells and following staining with Oil Red. For differentiation into osteogenic cells, cells were plated and cultured for 21 days in DMEM/F12 medium containing 10\% FBS, 10-7 M dexamethasone, 50 $\mu \mathrm{M}$ ascorbic acid-2 phosphate, and $10 \mathrm{mM} \beta$-glycerol phosphate (all purchased from Sigma-Aldrich). Osteogenic differentiation was confirmed by Alizarin red staining.

\section{Type 1 diabetic mouse model induced by streptozotocin (STZ)}

Mice aged 6-8 weeks old and weighing 25-30 g were used in the study. All procedures and manipulations were performed in accordance with instructions and approval of the Animal Care Committee. The mice were housed in $12 \mathrm{~h} \mathrm{light}$ $/ 12 \mathrm{~h}$ dark cycle and nourished accordingly. The mice were fasted for 6 hours before STZ injection. STZ was first dissolved in cooled $0.01 \mathrm{M}$ citrate buffer at $\mathrm{pH}$ 4.5. Type 1 diabetes in mice was induced by single intraperitoneal injection of STZ (Santa Cruz Biotechnology, Dallas, TX), at a concentration of $100 \mathrm{mg} / \mathrm{kg}$. Mouse blood glucose was examined by One Touch Ultra (Lifescan/ Johnson \& Johnson, New Brunswick, NJ). Onset of diabetes was defined as when glucose levels stably surpassed $300 \mathrm{mg} / \mathrm{dL}$ in 3 weeks.

\section{UC-MSC transplantation}

At day 21 after STZ injection, the mice which were confirmed to have diabetes were intravenously given $2 \times 10^{6}$ UC-MSCs in $200 \mu \mathrm{L}$ volume in sterile PBS. The treated mice were monitored for change in weight, blood glucose level, and serum insulin, as well as by glucose tolerance testing and evaluation of the structure of pancreatic islets.

\section{Glucose and insulin tolerance tests}

The mice were fasted $12 \mathrm{~h}$ before the glucose tolerance test. D-glucose was intraperitoneally injected to mice ( $2 \mathrm{~g} / \mathrm{kg}$ body weight); and blood glucose levels were measured at $0,30,60$, and 120 minutes. The insulin was dissolved in PBS at a dose of $0.75 \mathrm{mg} / \mathrm{kg}$. The mice were measured for blood glucose 30 minutes before insulin injection; and at 0,30, 60, and 120 minutes after insulin treatment.

\section{Serum insulin measurement}

At the day 28, mouse blood was obtained from facial vein and the serum was collected by centrifugation at $3000 \mathrm{rpm}$ in 10 minutes at $4^{\circ} \mathrm{C}$. The transparent faint yellow serum was assessed for concentration of insulin by Mercodia Ultrasensitive Mouse Insulin ELISA (Uppsala, Sweden). The calibrator curve was 
constructed and the insulin concentrations from the samples were interpolated from the standard curve (Prism 6, GraphPad Software, San Diego).

\section{Histological analysis of pancreatic islet}

The harvested mouse pancreases were fixed in formalin and embedded in paraffin blocks. The 10 micrometer-thin sections were stained with Hematoxylin \& Eosin following the standard established procedure. The islet structure was observed under microscopy and images were analyzed by Axio Vision Microscopy Software (Carl-Zeiss, Germany). For immunofluorescence staining, the mouse pancreases were fixed in $4 \%$ paraformaldehyde, treated with sucrose, and embedded in optimal cutting temperature compound (OCT). The 10 micrometer samples were dipped in $5 \%$ bovine serum albumin overnight at $4^{\circ} \mathrm{C}$. The blocked slides were incubated with insulin antibody (Goat anti-Rabbit Alexa Fluor 488, Sigma) overnight at $4^{\circ} \mathrm{C}$, then stained with FITC-conjugated secondary antibody (sc-2012, Santa Cruz Biotechnology) for 2 hours. Finally, the sections were stained with 4',6-diamidino-2-phenylindole (DAPI) (Santa Cruz Biotechnology) for nucleus staining and observed by fluorescence microscopy (Cell Observer, Carl-Zeiss, Germany).

\section{Data analysis}

The data were analyzed for statistical significance using GraphPad Prism software. Data were presented as mean \pm SEM. When applicable, a Student's unpaired t-test and one-way ANOVA were used to determine significance; $p<0.05$ was considered to be statistically significant.

\section{Results}

\section{Successful isolation and characterization of umbilical cord derived mesenchymal stem cells}

Umbilical cord tissues were cultured according to a protocol established by us (Van Pham et al., 2016). After 5-7 days, the MSC candidates emigrated from the tissues and exhibited a fibroblast-like shape. The cells rapidly proliferated from day 10 onward and reached confluence at day 15 . The cells were sub-cultured to the $5^{\text {th }}$ passage to produce a homogenous population. These cells were characterized for expression of MSC surface markers. Flow cytometry analysis showed that UC-MSC candidates strongly expressed CD44, CD73 and CD90, but did not express CD14, CD34, CD45 and HLA-DR. The cells also successfully differentiated into three kinds of mesoderm derived cells: osteoblasts, chondrocytes and adipocytes. During differentiation into osteoblasts, the UCMSCs changed their shape, accumulated calcium $\left(\mathrm{Ca}^{+2}\right)$ and magnesium 
$\left(\mathrm{Mg}^{2+}\right)$, and stained positive with alizarin red. The cells also successfully differentiated into chondrocytes, staining positive with Safranin O. They also differentiated into adipocytes, staining positive for Oil Red. These results were similar to the previous publication (Pham et al., 2016; Van Pham et al., 2016).

\section{UC-MSCs significantly improve diabetes in a Type 1 diabetes mellitus mouse model}

\section{Weight of mice after transplantation}

Mice treated with UC-MSC transplantation gradually increased their body weight from $28 \pm 6.77 \mathrm{~g} /$ mouse at day 0 (before treatment) to $31.07 \pm 8.63 \mathrm{~g} / \mathrm{mouse}$ at day 28 (post treatment) and $41.95 \pm 2.07 \mathrm{~g} /$ mouse at day 56 (post treatment) (Fig. 1). This means that the body weight of treated mice significantly increased after 2 months of treatment, compared to before treatment $(41.95 \pm 2.07 \mathrm{~g} /$ mouse vs $28 \pm 6.77 \mathrm{~g} /$ mouse, respectively). Conversely, in the placebo group where mice were injected with saline, their body weight gradually decreased from $26.28 \pm 0.89 \mathrm{~g} / \mathrm{mouse}$ at day 0 (before treatment) to $23.83 \pm 1.23 \mathrm{~g} / \mathrm{mouse}$ at day 28 (post treatment) and to $22.3 \pm 0.52 \mathrm{~g} / \mathrm{mouse}$ at day 56 (post treatment). Taken together, these results demonstrate that there was a clear effect of UCMSC transplantation on body weight recovery. After 2 months, treated mice recovered their body weight while placebo mice reduced their body weight (Fig. 1).

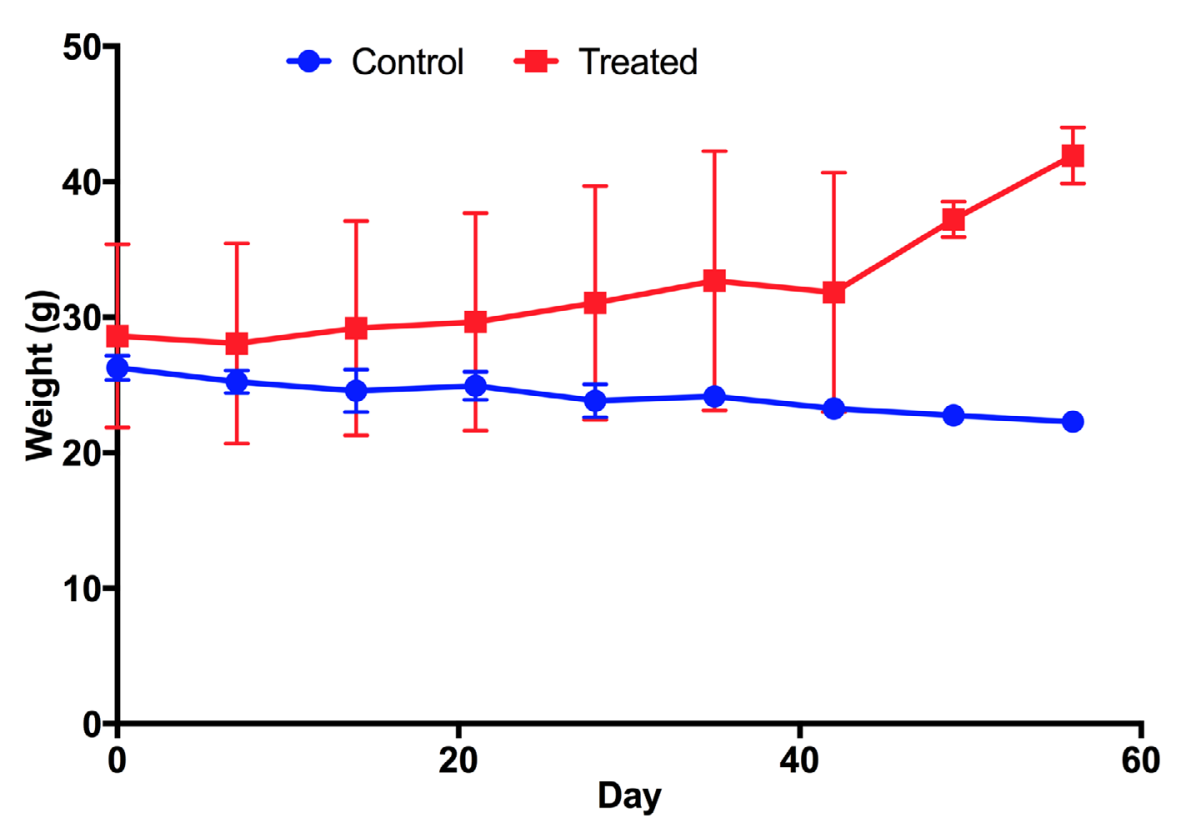

Figure 1. Changes in mouse body weight of treated mice versus placebo mice after stem cell transplantation. Mice treated with stem cells showed a gradual increase in body weight after 2 months (red line), while mice treated with placebo showed a gradual decrease in body weight (blue line). 


\section{Blood glucose levels of mice after transplantation}

The blood glucose in both treatment and placebo groups underwent significant changes during the experiment. In the treatment group, the blood glucose levels strongly decreased after 21 days of treatment - from $399.17 \pm 79.24 \mathrm{mg} /$ $\mathrm{dL}$ at day 0 (before treatment) to $334.83 \pm 105.43 \mathrm{mg} / \mathrm{dL}$ at day 21 (post treatment). However, at day 28, there was a slight increase of blood glucose, from $334.83 \pm 105.43 \mathrm{mg} / \mathrm{dL}$ to $343.83 \pm 118.07 \mathrm{mg} / \mathrm{dL}$; this increase was not statistically significantly $(p>0.05)$. The level of blood glucose was maintained from day 21 to day 42, then remarkably decreased at day 49 (to $255.5 \pm 80.37$ $\mathrm{mg} / \mathrm{dL}$ ). The achievement in reduction of blood glucose levels in diabetic mice suggested that the diabetic mice were recovering. However, we did see a slight increase of blood glucose at day $56(314.75 \pm 138.71 \mathrm{mg} / \mathrm{dL})$ when compared to day 49 (255.5 $\pm 80.37 \mathrm{mg} / \mathrm{dL})$, but non-significant $(p>0.05)$. In the placebo group, the blood glucose levels not only decreased but also gradually increasedfrom $370.33 \pm 57.78 \mathrm{mg} / \mathrm{dL}$ at day 0 (before treatment) to $517.67 \pm 52.73 \mathrm{mg} / \mathrm{dL}$ at day 56 (post treatment) (Fig. 2).

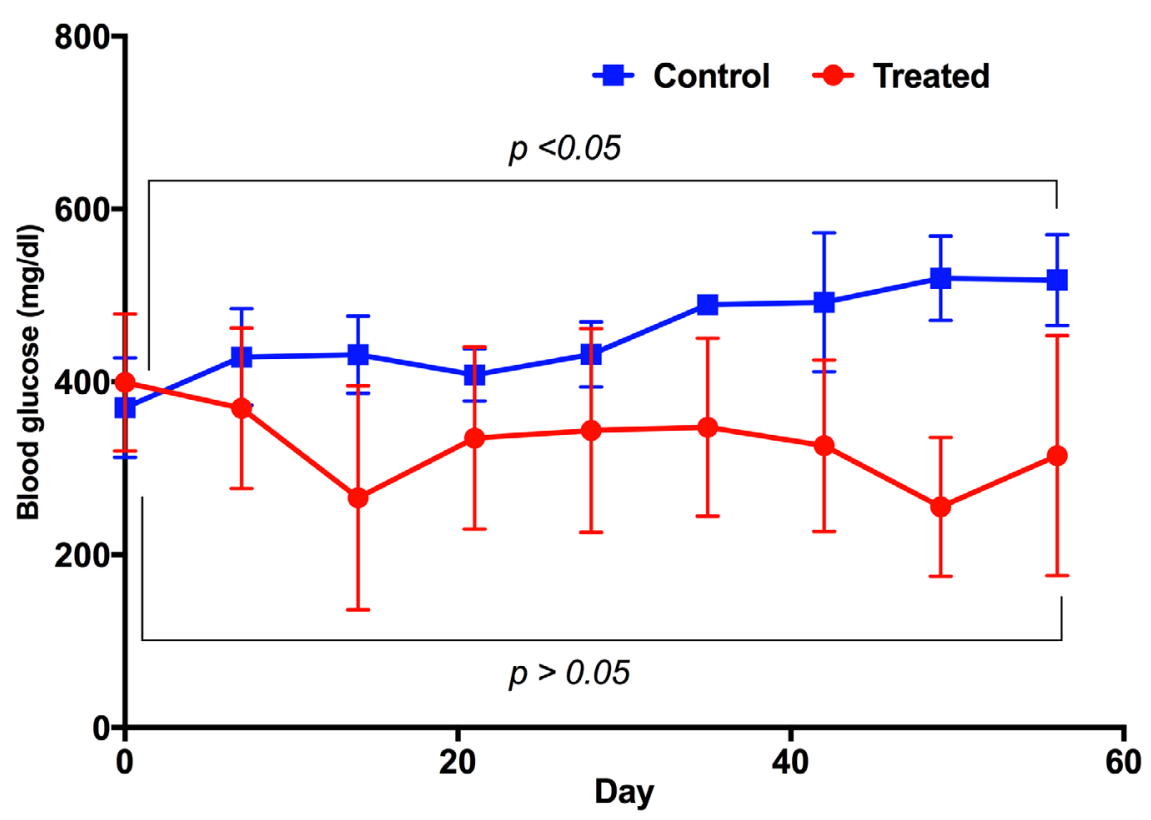

Figure 2. Changes in blood glucose levels of treated mice versus placebo mice after stem cell transplantation. UC-MSC transplantation reduced blood glucose levels of treated mice (red line). Blood glucose levels gradually increased in the placebo mice injected with saline (blue line).

\section{Glucose tolerance test}

After 28 days of treatment, mice from the treatment and placebo groups were subjected to glucose tolerance testing to determine the glucose absorbance of mice; normal (i.e. untreated) mice were used as positive controls. Figure 3 
shows that the responses of mice of each of the groups were different. Untreated mice were able to take in glucose after $1 \mathrm{~h}$, then glucose levels dropped to normal levels, similar to the level before glucose injection (Fig. 3; black line). In the placebo group, although the glucose level decreased after 60 mins, this level was maintained for 120 mins (Fig. 3; blue line). This means that absorbance of glucose in the placebo group was low. Unlike the placebo mice, the UC-MSC treated mice showed strong intake of glucose at 120 mins after glucose injection. The glucose level then returned back to the level before glucose injection (Fig. 3; red line).

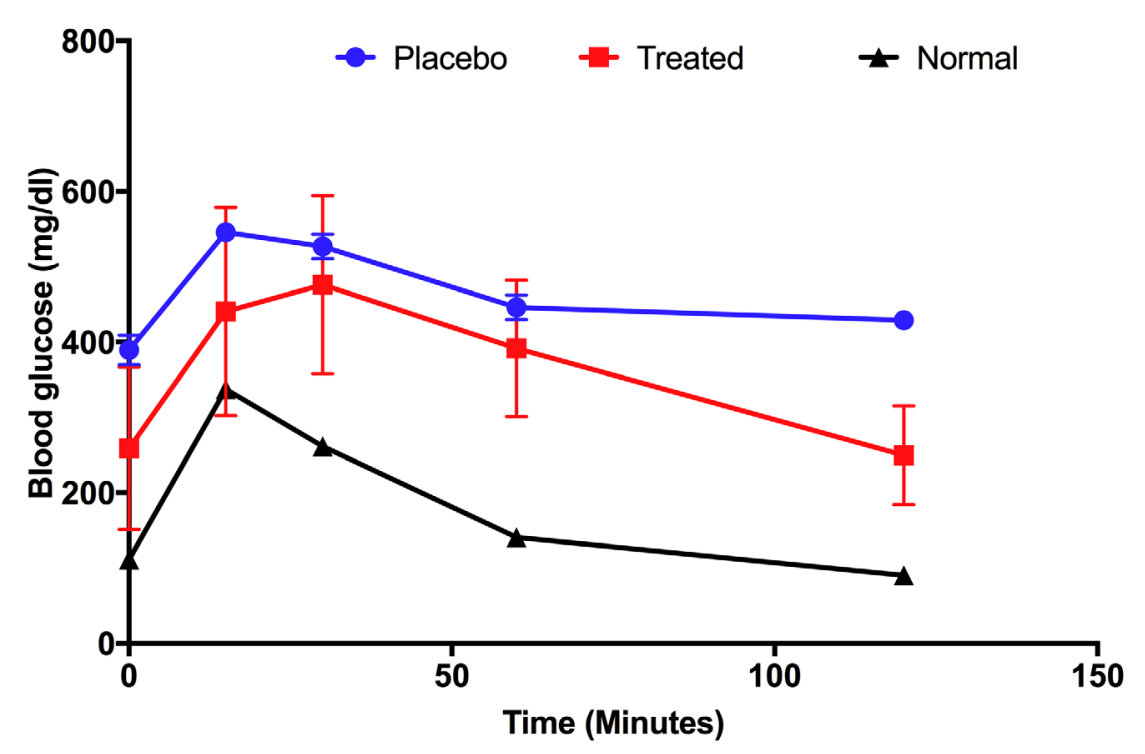

Figure 3. Glucose tolerance tests for mice in the UC-MSC treated, untreated (placebo) groups. Normal mice showed strong glucose uptake at $2 \mathrm{~h}$ after injection (black line). Placebo mice showed weak glucose uptake; after $1 \mathrm{hr}$ mice could not absorb any more glucose (blue line). UC-MSC treated mice showed good glucose absorbance (red line).

\section{Murine insulin in peripheral blood}

The level of insulin that exists in the peripheral blood reflects the recovery of the pancreas after treatment. At day 28 after treatment, peripheral blood was collected to determine the concentration of insulin. The results showed that the insulin concentration of treated mice significantly increased compared to placebo mice (1.139 $\pm 0.050 \mathrm{ug} / \mathrm{L}$ vs $0.30 \pm 0.084 \mathrm{ug} / \mathrm{L}$, respectively; $p<0.05)$ (Fig. 4). More importantly, the insulin concentration of treated mice at day 28 post treatment was not significant differently than normal mice (1.139 \pm 0.050 ug/L vs $1.118 \pm 0.095 \mathrm{ug} / \mathrm{L}$, respectively, $\mathrm{p}>0.05$ ) (Fig. 4). These results show that UC-MSC transplantation helped diabetic mice recover function of their pancreas. 


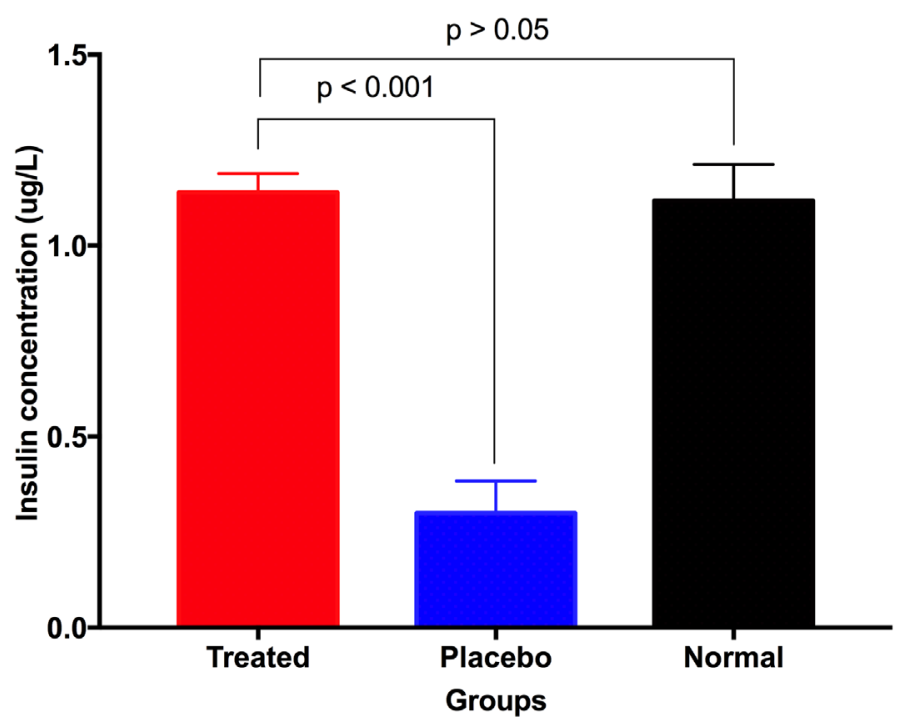

Figure 4. Insulin concentration in peripheral blood of mice in treated, untreated and placebo groups. The insulin concentration of treated mice (red column) significantly increased compared to placebo group (blue column) at 28 days post treatment. The treated mice had similar insulin concentration to normal (untreated) mice (black column).

\section{Recovery of murine pancreatic islets after UC-MSC transplantation}

The regeneration of pancreatic islets were evaluated by Hematoxylin \& Eosin $(H \& E)$ staining and anti-insulin antibody staining of pancreas. H\&E staining showed that STZ treated mice had injured islets and presence of pleomorphic cells (green arrow), necrotic cells (red arrow) and infiltrated lymphocytes (yellow arrow) (Fig. 5). The regeneration of Langerhans islets could be observed in the pancreas of treated mice and were similar to normal mice (Fig. 5).

The anti-insulin antibody staining showed that insulin positive cells disappeared in placebo mice, while the signal of insulin was very clear in islets of normal (untreated) mice. The injured pancreases were regenerated after UC-MSC transplantation at 28 days post treatment. Indeed, at 28 days post transplantation, insulin positive cells appeared in the pancreas of treated mice but not in the pancreas of placebo mice (Fig. 5). Overall, these results demonstrate that islets gradually recovered in the pancreases of UC-MSC treated mice.

\section{Discussion}

Type 1 diabetes mellitus accounts for about 5\% of diabetic patients. Type 1 diabetes mellitus has been shown to be an autoimmune disease in which the host's immune system attacks the host pancreas, reducing the Langerhans islets 
as well as beta cells (Eisenbarth, 2005; Notkins and Lernmark, 2001). Insulin injection is considered as an effective method to treat T1D. However, with this method, patients must be supplied insulin for the entire duration of their life. Stem cell transplantation can rescue the pancreas from autoimmune disease by two strategies: replacement of the immune system with HSCT or immune modulation that selectively suppresses the immune system. In this study, we successfully modulated the immune system by MSC transplantation to treat T1D in a mouse model.

Normal
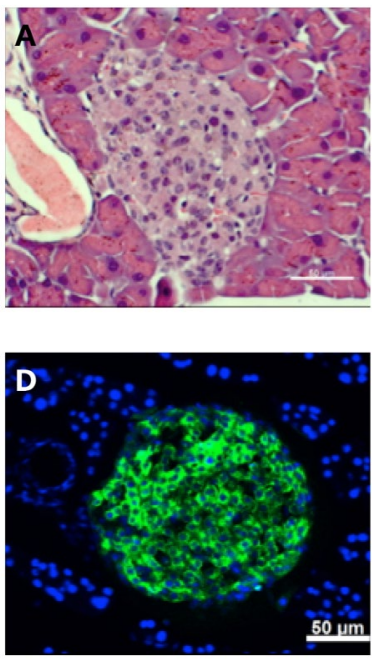

STZ treated
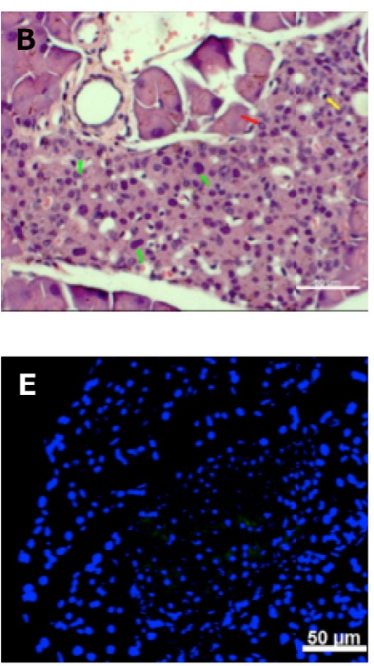

UC-MSC treated
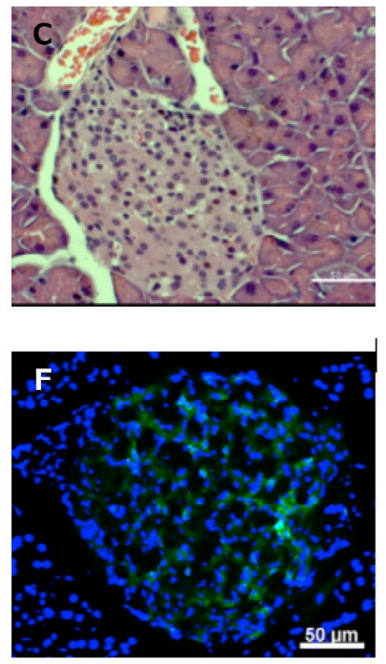

Figure 5. Histology of mouse interlobular islets. Pancreatic islets stained with Hematoxylin \& Eosin; (A) The homo-morphologic pale purple islet cells in normal pancreas; (B) the diabetic Langerhans islet with pleomorphic cells (green arrow), necrotic cells (red arrow) and infiltrated lymphocytes (yellow arrow); and (C) the recovery islet from stem cell-treated mouse with a few inflammatory cells (Magnification $\times 400$, scale bar $=50 \mu \mathrm{m}) ;(D, E, F)$ : Immunofluorescent images of insulin-stained islets (Magnification $\times 200$, scale bar $=50 \mu \mathrm{m}$ ).

Firstly, we successfully isolated and cultured umbilical cord derived UC-MSCs. These cells satisfied all criteria of MSCs that Dominici et al. have suggested (Dominici et al., 2006). Indeed, the cells exhibited the fibroblast-like shape when cultured as adherent cells in plastic flasks. They also expressed the MSC marker profile, which includes expression of CD44, CD73 and CD90, but absence of hematopoietic markers, e.g. CD34, CD45, CD14 and HLA-DR. With regard to the differentiation potential of these cells, we found that they could be successfully differentiated into mesoderm derived cells, including osteoblasts, chondrocytes and adipocytes. 
The UC-MSCs were used to treat T1D mice. The results showed that UC-MSC transplantation successfully rescued the pancreas which had been injured by STZ. Indeed, all treated mice exhibited an increase in body weight and decrease in blood glucose levels. These changes suggest that the metabolism of the UCMSC treated mice significantly improved such that the mice could absorb the glucose and maintain water in their cells, leading to the increase in body weight. More importantly, the significant increase of insulin in peripheral blood confirmed that in the treated mice, beta cells could produce insulin again. The glucose tolerance test also supported this observation; treated mice could absorb glucose better than placebo mice. The results from H\&E staining and anti-insulin antibody staining for islets emphasize again that treated mice successfully regain pancreatic function.

Successful regeneration of the pancreas is connected to UC-MSC transplantation. We hypothesized that grafted UC-MSCs might suppress pancreatic inflammation caused by STZ. Indeed, STZ contains a glucose molecule (in deoxy form) that is linked to a highly reactive methylnitrosourea moiety that is thought to exert the cytotoxic effects of STZ, while the glucose moiety directs the chemical to the pancreatic $\beta$ cells (Johansson and Tjalve, 1978). STZ recognizes the GLUT2 receptor on $\beta$ cell plasma membranes (Lenzen, 2008). There are some mechanisms that STZ use to cause toxicity on beta cells. For instance, one mechanism may be mediated by the DNA alkylating activity of its methylnitrosourea moiety (LeDoux et al., 1986; Wilson et al., 1988). The transfer of the methyl group from STZ to the DNA molecule causes damage resulting in the fragmentation of the DNA (Yamamoto et al., 1981). Moreover, STZ has potential to act as an intracellular nitric oxide (NO) donor (Turk et al., 1993) and is involved in the minor generation of ROS, including superoxide and hydroxyl radicals originating from hydrogen peroxide dismutation during hypoxanthine metabolism (Nukatsuka et al., 1990). All the aforementioned effects of STZ can cause beta cell death and significant injury to the pancreas. The injuries rapidly trigger the immune system to react to and attack the pancreas.

In the Type 1 diabetic mouse model (induced by STZ), transplantation of UCMSCs can affect the T1D mice by at least 2 mechanisms. The first mechanism is suppression of inflammation as well as injury of islets related to STZ. The in vitro assays supported this mechanism. Immune cells (T cells) from murine peripheral blood could be suppressed by certain cytokines produced by UC-MSCs. This means that UC-MSCs can decrease or suppress the inflammation provoked by STZ damage to the pancreas.

In a previous study, we showed that UC-MSCs exhibited strong immune modulation capacity compared to bone marrow or adipose tissue derived mesenchymal stem cells (Pham et al., 2016). UC-MSCs could efficiently inhibit T cell proliferation via production of IFN-gamma, IL-1 beta, IL-2, and TNF-alpha; and PGE2 (Pham et al., 2016). The immune modulation of UC-MSCs on murine immune cells were also observed in other previously published studies (Chan et 
al., 2016; Fu et al., 2015). In endotoxin treated rats, Fu et al. (2015) demonstrated that the application of MSCs significantly reduced the levels of pro-inflammatory TNF- $\alpha$ and IL-1 $\beta$, and increased the levels of anti-inflammatory IL-10 in these rats (Fu et al., 2015). Recently, Chan et al. (2016) showed that UCMSCs effectively suppressed asthmatic symptoms, and that its immunomodulatory effect resulted primarily from suppressing the Th2 pathway in the animal model (Chan et al., 2016).

The second mechanism is related to paracrine effects of UC-MSCs. Some factors secreted by UC-MSCs can trigger the regeneration of the injured pancreas. In a previously published study by Zhou et al., the authors demonstrated in vitro that UC-MSCs could produce insulin-like growth factor 1 (IGF1) to support the islets (Zhou et al., 2015). UC-MSCs also provide a pool of varying kinds of growth factors, including matrix metalloproteinase-2, matrix metalloproteinase-9, hepatocyte growth factor, transforming growth factor $\beta 1$, granulocyte-colony stimulating factor, fibroblast growth factor 2 and interleukin-6 (Santos et al., 2015). Based on these mechanisms, Zanier et al. have suggested that UC-MSCs can protect the murine brain after trauma (Zanier et al., 2011) and impact traumatic brain injury in humans (Wang et al., 2013).

Indeed, UC-MSCs can promote the regeneration of the injured pancreas. The role of pancreas regeneration also depends on the local pancreatic progenitor cells inside the pancreas. Via immunomodulatory factors secreted by UC-MSCs, pancreatic progenitor cells can be induced to proliferate and differentiate into beta cells which produce insulin, leading to an increase of insulin concentration in peripheral blood. In mice the islets of Langerhans (insulin positive cells) reappeared after 28 days of UC-MSC transplantation. The existence of pancreatic progenitor cells were confirmed by other studies (Hori et al., 2008; Oshima et al., 2007), suggesting that these cells could mature to become beta cells (Ma et al., 2012).

\section{Conclusion}

In this study, we show that UC-MSCs are easily isolated and cultured for transplantation applications. The cells maintained mesenchymal stem cell phenotypes after 5 passages in culture. Transplantation of these cells could significantly led to improvement in T1D mouse model of diabetes induced by STZ. UC-MSC treated mice recovered their body weight, blood insulin levels and blood glucose levels. More importantly, the function of pancreas was reactivated with insulin positive cells which existed in the mouse pancreases. This regeneration of injured pancreas was related to immune modulation and secreted trophic factors of UC-MSCs. Our findings suggest that UC-MSC transplantation is a suitable and promising treatment for type 1 diabetes mellitus. 


\section{Biomedical \\ Research \& Therapy}

ISSN: 2198-4093

\section{Abbreviations}

BM: Bone marrow

GVHD: Graft-versus-host disease

H\&E: Hematoxylin \& Eosin

HLA: Human leukocyte antigens

HSCT: Hematopoietic stem cell transplantation

MSCs: Mesenchymal stem cells

STZ: Streptozotocin

T1D: Type 1 diabetes mellitus disease

UC-MSCs: Umbilical cord derived MSCs

\section{Acknowledgment}

This research was funded by Ministry of Science and Technology via project Grant No. DTDL.2012-G/23.

\section{Author Contribution}

NKP, BTBL isolated and confirmed UC-MSCs and wrote and revised the paper; the cell products have been prepared by TCNhat and BTVAnh; transplantation procedure and the monitor of body weight, blood glucose and glucose tolerance have been performed by NLTCong and BNTAnh; serum insulin measurement and pancreas structure evaluation carried out by DTTLoan and NLTCong. 


\section{References}

Aggarwal, S., and Pittenger, M.F. (2005). Human mesenchymal stem cells modulate allogeneic immune cell responses. Blood 105, 1815-1822.

Association, A.D. (2006). Diagnosis and classification of diabetes mellitus. Diabetes care 29, S43.

Bartholomew, A., Sturgeon, C., Siatskas, M., Ferrer, K., Mclntosh, K., Patil, S., Hardy, W., Devine, S., Ucker, D., Deans, R., et al. (2002). Mesenchymal stem cells suppress lymphocyte proliferation in vitro and prolong skin graft survival in vivo. Exp Hematol 30, 42-48.

Burt, R.K., Oyama, Y., Traynor, A., and Kenyon, N.S. (2002). Hematopoietic stem cell therapy for type 1 diabetes: induction of tolerance and islet cell neogenesis. Autoimmunity reviews 1, 133-138.

Chan, C.K., Lin, T.C., Huang, Y.A., Chen, Y.S., Wu, C.L., Lo, H.Y., Kuo, M.L., Wu, K.H., and Huang, J.L. (2016). The modulation of Th2 immune pathway in the immunosuppressive effect of human umbilical cord mesenchymal stem cells in a murine asthmatic model. Inflamm Res 65, 795-801.

Chen, G.L., Paplham, P., and McCarthy, P.L. (2014). Remestemcel-L for acute graft-versushost disease therapy. Expert Opin Biol Ther 14, 261-269.

Chhabra, P., and Brayman, K.L. (2013). Stem cell therapy to cure type 1 diabetes: from hype to hope. Stem Cells Transl Med 2, 328-336.

Dominici, M., Le Blanc, K., Mueller, I., Slaper-Cortenbach, I., Marini, F., Krause, D., Deans, R., Keating, A., Prockop, D., and Horwitz, E. (2006). Minimal criteria for defining multipotent mesenchymal stromal cells. The International Society for Cellular Therapy position statement. Cytotherapy 8, 315-317.

Eisenbarth, G.S. (2005). Type 1 diabetes mellitus. Joslin's diabetes mellitus 14, 399-424.

Froud, T., Ricordi, C., Baidal, D.A., Hafiz, M.M., Ponte, G., Cure, P., Pileggi, A., Poggioli, R., Ichii, H., and Khan, A. (2005). Islet transplantation in type 1 diabetes mellitus using cultured islets and steroid-free immunosuppression: Miami experience. American Journal of Transplantation 5, 2037-2046.

Fu, L., Liu, Y., Zhang, D., Xie, J., Guan, H., and Shang, T. (2015). Beneficial effect of human umbilical cord-derived mesenchymal stem cells on an endotoxin-induced rat model of preeclampsia. Exp Ther Med 10, 1851-1856.

Hori, Y., Fukumoto, M., and Kuroda, Y. (2008). Enrichment of putative pancreatic progenitor cells from mice by sorting for prominin1 (CD133) and platelet-derived growth factor receptor beta. Stem Cells 26, 2912-2920.

Johansson, E.B., and Tjalve, H. (1978). Studies on the tissue-disposition and fate of [14C]streptozotocin with special reference to the pancreatic islets. Acta Endocrinol (Copenh) 89, 339-351.

Konishi, A., Sakushima, K., Isobe, S., and Sato, D. (2016). First Approval of Regenerative Medical Products under the PMD Act in Japan. Cell Stem Cell 18, 434-435.

Kurtzberg, J., Prockop, S., Teira, P., Bittencourt, H., Lewis, V., Chan, K.W., Horn, B., Yu, L., Talano, J.A., Nemecek, E., et al. (2014). Allogeneic human mesenchymal stem cell therapy (remestemcel-L, Prochymal) as a rescue agent for severe refractory acute graftversus-host disease in pediatric patients. Biol Blood Marrow Transplant 20, 229-235. 
LeDoux, S.P., Woodley, S.E., Patton, N.J., and Wilson, G.L. (1986). Mechanisms of nitrosourea-induced beta-cell damage. Alterations in DNA. Diabetes 35, 866-872.

Lenzen, S. (2008). The mechanisms of alloxan- and streptozotocin-induced diabetes. Diabetologia 51, 216-226.

Ma, F., Chen, F., Chi, Y., Yang, S., Lu, S., and Han, Z. (2012). Isolation of pancreatic progenitor cells with the surface marker of hematopoietic stem cells. Int $J$ Endocrinol 2012, 948683.

Nathan, D.M. (1993). Long-term complications of diabetes mellitus. New England Journal of Medicine 328, 1676-1685.

Notkins, A.L., and Lernmark, А̊. (2001). Autoimmune type 1 diabetes: resolved and unresolved issues. The Journal of clinical investigation 108, 1247-1252.

Nukatsuka, M., Yoshimura, Y., Nishida, M., and Kawada, J. (1990). Allopurinol protects pancreatic beta cells from the cytotoxic effect of streptozotocin: in vitro study. $J$ Pharmacobiodyn 13, 259-262.

Oshima, Y., Suzuki, A., Kawashimo, K., Ishikawa, M., Ohkohchi, N., and Taniguchi, H. (2007). Isolation of mouse pancreatic ductal progenitor cells expressing CD133 and cMet by flow cytometric cell sorting. Gastroenterology 132, 720-732.

Pham, P.V., Vu, N.B., and Phan, N.K. (2016). Umbilical cord-derived stem cells (MODULATISTTM) show strong immunomodulation capacity compared to adipose tissue-derived or bone marrow-derived mesenchymal stem cells. Biomedical Research and Therapy 3, 10.

Rasmusson, I. (2006). Immune modulation by mesenchymal stem cells. Experimental cell research 312, 2169-2179.

Rother, K.I., and Harlan, D.M. (2004). Challenges facing islet transplantation for the treatment of type 1 diabetes mellitus. The Journal of clinical investigation 114, 877-883.

Santos, J.M., Camoes, S.P., Filipe, E., Cipriano, M., Barcia, R.N., Filipe, M., Teixeira, M., Simoes, S., Gaspar, M., Mosqueira, D., et al. (2015). Three-dimensional spheroid cell culture of umbilical cord tissue-derived mesenchymal stromal cells leads to enhanced paracrine induction of wound healing. Stem Cell Res Ther 6, 90.

Shapiro, A.J., Lakey, J.R., Ryan, E.A., Korbutt, G.S., Toth, E., Warnock, G.L., Kneteman, N.M., and Rajotte, R.V. (2000). Islet transplantation in seven patients with type 1 diabetes mellitus using a glucocorticoid-free immunosuppressive regimen. New England Journal of Medicine 343, 230-238.

Tripathi, B.K., and Srivastava, A.K. (2006). Diabetes mellitus: Complications and therapeutics. Medical Science Monitor 12, RA130-RA147.

Turk, J., Corbett, J.A., Ramanadham, S., Bohrer, A., and McDaniel, M.L. (1993). Biochemical evidence for nitric oxide formation from streptozotocin in isolated pancreatic islets. Biochem Biophys Res Commun 197, 1458-1464.

Van Pham, P., Truong, N.C., Le, P.T., Tran, T.D., Vu, N.B., Bui, K.H., and Phan, N.K. (2016). Isolation and proliferation of umbilical cord tissue derived mesenchymal stem cells for clinical applications. Cell Tissue Bank 17, 289-302.

Voltarelli, J.C., Couri, C.E., Stracieri, A.B., Oliveira, M.C., Moraes, D.A., Pieroni, F., Coutinho, M., Malmegrim, K.C., Foss-Freitas, M.C., and Simoes, B.P. (2007). Autologous nonmyeloablative hematopoietic stem cell transplantation in newly diagnosed type 1 diabetes mellitus. Jama 297, 1568-1576. 
Wang, S., Cheng, H., Dai, G., Wang, X., Hua, R., Liu, X., Wang, P., Chen, G., Yue, W., and An, Y. (2013). Umbilical cord mesenchymal stem cell transplantation significantly improves neurological function in patients with sequelae of traumatic brain injury. Brain Res 1532, 76-84.

Wilson, G.L., Hartig, P.C., Patton, N.J., and LeDoux, S.P. (1988). Mechanisms of nitrosourea-induced beta-cell damage. Activation of poly (ADP-ribose) synthetase and cellular distribution. Diabetes 37, 213-216.

Yamamoto, H., Uchigata, Y., and Okamoto, H. (1981). Streptozotocin and alloxan induce DNA strand breaks and poly(ADP-ribose) synthetase in pancreatic islets. Nature 294, 284-286.

Zanier, E.R., Montinaro, M., Vigano, M., Villa, P., Fumagalli, S., Pischiutta, F., Longhi, L., Leoni, M.L., Rebulla, P., Stocchetti, N., et al. (2011). Human umbilical cord blood mesenchymal stem cells protect mice brain after trauma. Crit Care Med 39, 2501-2510.

Zhou, Y., Hu, Q., Chen, F., Zhang, J., Guo, J., Wang, H., Gu, J., Ma, L., and Ho, G. (2015). Human umbilical cord matrix-derived stem cells exert trophic effects on beta-cell survival in diabetic rats and isolated islets. Dis Model Mech 8, 1625-1633. 